\title{
Predicting Factors for Pelvic Lymph Node Metastasis in Patients with Apparently Early-Stage Endometrial Cancer
}

\author{
Pariyed Gumtorntip $^{1}$, Yenrudee Poomtavorn ${ }^{2 *}$, Chamnan Tanprasertkul ${ }^{3}$
}

\begin{abstract}
Background: Performing lymphadenectomy in all patients with early-stage endometrial cancer (EC) is debatable because the procedure may expose patients to unnecessary risks of postoperative complications. Aim of this study was to evaluate the prevalence and risk factors of pelvic lymph node metastasis (PLNM) in patients with apparently early-stage EC. Materials and methods: Two hundred and two patients with apparently early-stage EC who underwent surgical staging at Thammasat University Hospital between the years 2013 and 2020 were included in this retrospective study. Clinicopathological data and preoperative laboratory results were obtained from computer-based medical records. All data were statistically analyzed to determine the prevalence of PLNM and risk factors for developing PLNM. Results: PLNM was detected in $22(10.9 \%)$ patients. Univariate analysis demonstrated that having grade 3 tumor, myometrial invasion of $50 \%$ or greater, vaginal involvement, cervical involvement, adnexal involvement, lower uterine segment involvement, lymphovascular space invasion (LVSI), and positive peritoneal cytology were associated with higher risk for developing PLNM. In addition, lower preoperative hemoglobin level and higher preoperative white blood cell count were significantly associated with PLNM. Multivariate analysis demonstrated that myometrial invasion of $50 \%$ or greater and LVSI were independent risk factors for developing PLNM (odds ratio (OR) 9.31, 95\% confidence interval (CI) 2.58-33.55, $\mathrm{p}=0.001$, and OR 3.73, 95\%CI 1.39-10.02, $\mathrm{p}=0.009$, respectively). Conclusions: Myometrial invasion of $50 \%$ or greater and LVSI were independent risk factors for developing PLNM in patients with apparently early-stage EC and thus lymphadenectomy in these patients should be provided.
\end{abstract}

Keywords: Endometrial cancer- risk factors- pelvic lymph node metastasis- lymphadenectomy

Asian Pac J Cancer Prev, 23 (2), 617-622

\section{Introduction}

Endometrial cancer (EC) is the most prevalent gynecologic malignancy in the developed countries with the incidence of approximately 12.9 patients per 100,000 women (Jemal et al., 2011). In Thailand, EC is the third most common gynecologic malignancy with the age-standardized incidence rate of 4.3 cases per 100,000 women (Khuhaprema et al., 2007). Women with prolonged unopposed estrogen stimulation, late menopause, infertility, diabetes mellitus and hypertension, and overweight women are at increased risk for developing EC.

Approximately $70 \%$ of patients with EC are diagnosed with stage I disease. In early-stage EC, surgery is often curative, with a 5-year-survival rate of greater than $90 \%$. The occurrence of pelvic lymph node metastasis ranges from $10.5 \%$ to $14.9 \%$ (Lee et al., 2016; Karalok et al., 2017; Sari et al., 2017). Intraabdominal lymph node metastasis are often associated with poor prognosis and thus require adjuvant chemotherapy and radiotherapy (Shah et al., 2011).

Concerning the recommendations of the current National Comprehensive Cancer Network (NCCN) guidelines 2021, a combination of hysterectomy with bilateral salpingo-oophorectomy, along with lymph node assessment is the mainstay treatment of EC (NCCN, 2021). However, the therapeutic benefits of pelvic and para-aortic lymphadenectomy are still debatable. Data from the two randomized controlled trials (Benedetti Panici et al., 2008; Kitchener et al., 2009) did not support the therapeutic benefit of lymphadenectomy in early-stage EC. In contrast, data from the retrospective study suggested that patients who underwent systematic lymphadenectomy had improved survival rate as compared with those who had no sampling performed (Kilgore et al., 1995). According to the two previously-mentioned randomized controlled trials (Benedetti Panici et al., 2008; Kitchener et al., 2009), the overall survival and recurrence-free survival rates were not increased among patients with early-stage EC who

${ }^{1}$ Department of Obstetrics and Gynecology, Faculty of Medicine, Thammasat University Hospital, Pathumthani 12120, Thailand. ${ }^{2}$ Gynecologic Oncology Unit, Department of Obstetrics and Gynecology, Faculty of Medicine, Thammasat University Hospital, Pathumthani 12120, Thailand. ${ }^{3}$ Department of Obstetrics and Gynecology, Faculty of Medicine, Thammasat University, Thailand. *For Correspondence: pyenrudee@gmail.com 
underwent pelvic lymphadenectomy, while neurovascular injury, pelvic infection, lymphocyst and lymphedema formation rates were increased. Regarding those complications, some of them were potentially irreversible and might have a negative impact on long-term quality of life of the patients (Achouri et al., 2013; Hareyama et al., 2015). The European Society of Gynaecological Oncology (ESGO), the European Society for Radiotherapy and Oncology (ESTRO), and the European Society of Pathology (ESP) guidelines (Concin et al., 2021) recommend against lymphadenectomy in patients with low and intermediate risk, early-stage EC owing to low rate of lymph node invasion in these groups of patients and high risk for developing morbidity following the surgical procedure. Therefore, performing lymphadenectomy in all patients with early-stage EC is debatable because the procedure may expose patients to unnecessary risks of postoperative complications.

The aim of this study was to evaluate the prevalence of pelvic lymph node metastasis (PLNM) in patients with early-stage EC and the possible risk factors for developing PLNM in these patients. Determining the risk factors would help in identifying patients who might benefit from undergoing lymphadenectomy and avoid unnecessary procedure and thus postoperative complications.

\section{Materials and Methods}

This retrospective study was conducted at Thammasat University Hospital, a tertiary care, teaching hospital in Pathumthani, Thailand. The study protocol was approved by the ethics committee of Thammasat University.

Patients with apparently early-stage EC who underwent total abdominal hysterectomy, bilateral salpingooophorectomy, and pelvic lymphadenectomy with or without para-aortic lymphadenectomy at Thammasat Hospital between the years 2013 and 2020 were enrolled. Apparently early-stage EC (clinical stages I and II) was defined as the disease which was confined to the uterus without evidence of metastasis. Patients who had preoperative evidence of extrauterine metastasis and no histological data were excluded. Their computer-based medical records were reviewed. Clinical characteristics, including age, parity, and body mass index (BMI) were collected. Serum carbohydrate antigen 125 (CA-125), human epididymis protein 4 (HE4), complete blood count $(\mathrm{CBC})$ and routine preoperative blood tests were also collected.

Pathological characteristics including histological type, tumor grade, tumor size, lymph node status, myometrial invasion, lower uterine segment involvement (LUSI), vaginal involvement, cervical involvement, adnexal involvement, uterine serosa involvement, lymphovascular space invasion (LVSI), and peritoneal cytology were obtained. EC staging was determined according to the International Federation of Gynecology and Obstetrics (FIGO) 2009 staging for EC.

Continuous variables were non-normally distributed, so they were expressed as median (range) and compared using Mann-Whitney U test. For categorical variables, chi-squared test or Fisher's exact test was used to evaluate the associations between variables. Multivariate logistic regression analysis was used to identify independent risk factors for having PLNM. A p-value of less than 0.05 was considered statistically significant. Statistical Package for the Social Sciences, version 25.0 Software (SPSS Inc, Chicago, IL, USA) was used for statistical analysis.

\section{Results}

There were 365 women with EC who underwent surgery during the period of the study. Two hundred and two of them met the inclusion criteria and were included in the study. The clinicopathological characteristics of the enrolled patients are shown in Table 1. Their median (range) age was $60(31-85)$ years and the median (range) BMI was $25.8(15.0-54.7) \mathrm{kg} / \mathrm{m}^{2}$. Most patients had endometrioid histology $(80.7 \%)$. Grade I, II, and III tumors were found in $38(18.8 \%), 86(42.6 \%)$, and $78(38.6 \%)$ women, respectively. Myometrial invasion of $50 \%$ or greater and LVSI were detected in $80(39.6 \%)$ and 56 $(27.7 \%)$ patients, respectively. PLNM was detected in 22 (10.9\%) patients.

Univariate analysis demonstrated that the risk of PLNM was significantly increased in patients with grade 3 tumor $(\mathrm{p}=0.037)$, myometrial invasion of $50 \%$ or greater $(p<0.001)$, vaginal involvement $(p<0.001)$, cervical involvement $(p<0.001)$, adnexal involvement $(p<0.001)$, LUSI $(p=0.03)$, LVSI $(p<0.001)$, positive peritoneal cytology $(p=0.005)$, and preoperative serum CA-125 level of greater than $35 \mathrm{U} / \mathrm{mL}(\mathrm{p}=0.015)$. In addition, the pelvic lymph node-positive group had lower preoperative hemoglobin $(\mathrm{Hb})$ level than the pelvic lymph node-negative group (11.9 vs $12.5 \mathrm{~g} / \mathrm{dL}$, respectively, $\mathrm{p}=0.017$ ). Preoperative white blood cell count (WBC) count was significantly higher in the pelvic lymph nodepositive group as compared with the pelvic lymph nodenegative group $\left(8.4 \times 10^{3}\right.$ vs $7.3 \times 10^{3} / \mu \mathrm{L}$, respectively, $\mathrm{p}=0.043)$. In contrast, platelet count, absolute neutrophil count (ANC), absolute monocyte count (AMC), absolute lymphocyte count (ALC), neutrophil-lymphocyte ratio (NLR), monocyte-lymphocyte ratio (MLR), and platelet-lymphocyte ratio (PLR) had no significant correlations with PLNM (Table 2).

Multivariate analysis revealed that myometrial invasion of $50 \%$ or greater and LVSI were independent risk factors for developing PLNM in patients with apparently early-stage EC (odds ratio (OR) 9.31, 95\% confidence interval (CI) 2.58-33.55, p $=0.001$, and OR 3.73, 95\% CI $1.39-10.02, \mathrm{p}=0.009$, respectively) (Table 3 ).

\section{Discussion}

This study demonstrated the prevalence of PLNM at $10.9 \%$ (22 out of 202 patients) which is comparable to those of the previous studies (10.5-14.9\%) (Lee et al., 2016; Karalok et al., 2017; Sari et al., 2017).

Currently, several models have been proposed to predict lymph node metastasis in patients with EC. However, no definite consensus regarding the optimal model for using in clinical practice (Keys et al., 2004; Vargas et al., 2014; Bendifallah et al., 2014). Those 
DOI:10.31557/APJCP.2022.23.2.617

Lymph Node Metastasis in Endometrial CA

Table 1. Clinicopathological Characteristics of Apparently Early-Stage Endometrial Cancer Patients $(\mathrm{N}=202)$

\begin{tabular}{|c|c|}
\hline Characteristics & $\mathrm{N}(\%)$ \\
\hline Age (years), median (range) & $60(31-85)$ \\
\hline \multicolumn{2}{|l|}{ Parity } \\
\hline Nulliparous & $69(34.2)$ \\
\hline Multiparous & $133(65.8)$ \\
\hline BMI $\left(\mathrm{kg} / \mathrm{m}^{2}\right)$, median (range) & $25.8(15.0-54.7)$ \\
\hline \multicolumn{2}{|l|}{ Stage } \\
\hline I & $147(72.8)$ \\
\hline II & $22(10.9)$ \\
\hline III & $27(13.3)$ \\
\hline IV & $6(3)$ \\
\hline \multicolumn{2}{|l|}{ Histology } \\
\hline Endometrioid & $163(80.7)$ \\
\hline Non-endometrioid & $39(19.3)$ \\
\hline \multicolumn{2}{|l|}{ Tumor grade } \\
\hline I & $38(18.8)$ \\
\hline II & $86(42.6)$ \\
\hline III & $78(38.6)$ \\
\hline \multicolumn{2}{|l|}{ Tumor size } \\
\hline$<2 \mathrm{~cm}$ & $25(12.4)$ \\
\hline $2-4 \mathrm{~cm}$ & $80(39.6)$ \\
\hline$>4 \mathrm{~cm}$ & $97(48)$ \\
\hline \multicolumn{2}{|l|}{ Myometrial invasion } \\
\hline$<50 \%$ & $122(60.4)$ \\
\hline$\geq 50 \%$ & $80(39.6)$ \\
\hline \multicolumn{2}{|l|}{ Vaginal involvement } \\
\hline Yes & $2(1)$ \\
\hline No & $200(99)$ \\
\hline \multicolumn{2}{|l|}{ Cervical involvement } \\
\hline Yes & $39(19.3)$ \\
\hline No & $163(80.7)$ \\
\hline \multicolumn{2}{|l|}{ Adnexal involvement } \\
\hline Yes & $13(6.4)$ \\
\hline No & $189(93.6)$ \\
\hline \multicolumn{2}{|l|}{ LUSI } \\
\hline Yes & $85(42.1)$ \\
\hline No & $117(57.9)$ \\
\hline \multicolumn{2}{|l|}{ LVSI } \\
\hline Yes & $56(27.7)$ \\
\hline No & $146(72.3)$ \\
\hline \multicolumn{2}{|l|}{ Peritoneal cytology } \\
\hline Positive & $32(15.8)$ \\
\hline Negative & $170(84.2)$ \\
\hline \multicolumn{2}{|l|}{ Pelvic lymph node metastasis } \\
\hline Yes & $22(10.9)$ \\
\hline No & $180(89.1)$ \\
\hline
\end{tabular}

BMI, body mass index; LUSI, lower uterine segment involvement; LVSI, lymphovascular space invasion
Table 2. Univariate Analysis of Risk Factors for Pelvic Lymph Node Metastasis

\begin{tabular}{|c|c|c|c|}
\hline \multirow[t]{2}{*}{ Variables } & \multicolumn{2}{|c|}{ Pelvic lymph node } & \multirow[t]{2}{*}{ P-value } \\
\hline & $\begin{array}{l}\text { Positive } \\
(\mathrm{N}=22)\end{array}$ & $\begin{array}{l}\text { Negative } \\
(\mathrm{N}=180)\end{array}$ & \\
\hline \multicolumn{3}{|c|}{ BMI $\left(\mathrm{kg} / \mathrm{m}^{2}\right), \mathrm{N}(\%)$} & 0.859 \\
\hline$<30$ & $17(77.3)$ & $136(75.6)$ & \\
\hline$\geq 30$ & $5(22.7)$ & $44(24.4)$ & \\
\hline \multicolumn{3}{|l|}{ Pathology, N (\%) } & 0.32 \\
\hline Endometrioid & $16(72.7)$ & $147(81.7)$ & \\
\hline $\begin{array}{l}\text { Non- } \\
\text { endometrioid }\end{array}$ & $6(27.3)$ & $33(18.3)$ & \\
\hline \multicolumn{3}{|c|}{ Tumor grade, $\mathrm{N}(\%)$} & 0.037 \\
\hline $\begin{array}{l}\text { Low } \\
\text { (grade I-II) }\end{array}$ & $9(40.9)$ & $115(63.9)$ & \\
\hline $\begin{array}{l}\text { High (grade } \\
\text { III) }\end{array}$ & $13(59.1)$ & $65(36.1)$ & \\
\hline $\begin{array}{l}\text { Tumor size, } \\
\text { mean (SD), N } \\
(\%)\end{array}$ & $6.1(3.4)$ & $4.5(2.5)$ & 0.009 \\
\hline \multicolumn{3}{|c|}{ Myometrial invasion, $\mathrm{N}(\%)$} & $<0.001$ \\
\hline$<50 \%$ & $3(13.6)$ & $119(66.1)$ & \\
\hline$\geq 50 \%$ & $19(86.4)$ & $61(33.9)$ & \\
\hline \multicolumn{3}{|c|}{ Vaginal involvement, $\mathrm{N}(\%)$} & $<0.001$ \\
\hline Yes & $2(9.1)$ & $0(0)$ & \\
\hline No & $20(90.9)$ & $180(100)$ & \\
\hline \multicolumn{3}{|c|}{ Cervical involvement, $\mathrm{N}(\%)$} & $<0.001$ \\
\hline Yes & $14(63.6)$ & $25(13.9)$ & \\
\hline No & $8(36.4)$ & $155(86.1)$ & \\
\hline \multicolumn{3}{|c|}{ Adnexal involvement, N (\%) } & $<0.001$ \\
\hline Yes & $7(31.8)$ & $6(3.3)$ & \\
\hline No & $15(68.2)$ & $174(96.7)$ & \\
\hline \multicolumn{3}{|l|}{ LUSI, N (\%) } & 0.03 \\
\hline Yes & $14(63.6)$ & $71(39.4)$ & \\
\hline No & $8(36.4)$ & $109(60.6)$ & \\
\hline \multicolumn{3}{|l|}{ LVSI, N (\%) } & $<0.001$ \\
\hline Yes & $14(63.6)$ & $42(23.3)$ & \\
\hline No & $8(36.4)$ & $138(76.7)$ & \\
\hline \multicolumn{3}{|c|}{ Peritoneal cytology, $\mathrm{N}(\%)$} & 0.005 \\
\hline Positive & $8(36.4)$ & $24(13.3)$ & \\
\hline Negative & $14(63.6)$ & $156(86.7)$ & \\
\hline \multicolumn{3}{|c|}{ CA 125 level (U/mL), N (\%) } & 0.015 \\
\hline$\leq 35$ & $2(25)$ & $52(68)$ & \\
\hline$>35$ & $6(75)$ & $24(32)$ & \\
\hline $\begin{array}{l}\mathrm{Hb}(\mathrm{g} / \mathrm{dL}) \\
\text { median (range) }\end{array}$ & $11.9(10.2-12.6)$ & $12.5(11.4-13.4)$ & 0.017 \\
\hline $\begin{array}{l}\text { WBC } \\
\left(\mathrm{x} 10^{3} / \mu \mathrm{L}\right) \\
\text { median (range) }\end{array}$ & $8.4(7.1-9.2)$ & $7.3(6.1-8.8)$ & 0.043 \\
\hline $\begin{array}{l}\text { Platelets } \\
\left(\mathrm{x} 10^{3} / \mu \mathrm{L}\right) \\
\text { median (range) }\end{array}$ & $307.5(270-364)$ & $290.5(244.5-341)$ & 0.27 \\
\hline $\begin{array}{l}\text { ANC } \\
\left(\mathrm{x} 10^{3} / \mu \mathrm{L}\right) \\
\text { median (range) }\end{array}$ & $63.9(53.7-71.4)$ & $61.1(54.9-67.3)$ & 0.21 \\
\hline $\begin{array}{l}\mathrm{AMC} \\
\left(\mathrm{x} 10^{3} / \mu \mathrm{L}\right) \\
\text { median (range) }\end{array}$ & $7.1(6.0-8.2)$ & $6.9(5.8-8.1)$ & 0.7 \\
\hline
\end{tabular}

Asian Pacific Journal of Cancer Prevention, Vol 23 
Table 2. Continued

\begin{tabular}{|c|c|c|c|}
\hline \multirow[t]{2}{*}{ Variables } & \multicolumn{2}{|c|}{ Pelvic lymph node } & \multirow[t]{2}{*}{ P-value } \\
\hline & $\begin{array}{l}\text { Positive } \\
(\mathrm{N}=22)\end{array}$ & $\begin{array}{l}\text { Negative } \\
(\mathrm{N}=180)\end{array}$ & \\
\hline $\begin{array}{l}\text { ALC } \\
\left(\mathrm{x} 10^{3} / \mu \mathrm{L}\right), \\
\text { median } \\
\text { (range) }\end{array}$ & $24.4(19.1-27.8)$ & $27.5(22.0-33.8)$ & 0.092 \\
\hline $\begin{array}{l}\text { NLR, } \\
\text { median } \\
\text { (range) }\end{array}$ & $2.6(2.0-3.7)$ & $2.2(1.6-3.0)$ & 0.13 \\
\hline $\begin{array}{l}\text { MLR, } \\
\text { median } \\
\text { (range) }\end{array}$ & $0.3(0.2-0.4)$ & $0.2(0.2-0.3)$ & 0.19 \\
\hline $\begin{array}{l}\text { PLR, median } \\
\text { (range) }\end{array}$ & $151.1(113.7-210.1)$ & $139.1(111.0-180.1)$ & 0.5 \\
\hline \multicolumn{4}{|c|}{$\begin{array}{l}\text { BMI, body mass index; LUSI, lower uterine segment involvement; } \\
\text { LVSI, lymphovascular space invasion; CA-125, carbohydrate antigen } \\
\text { 125; Hb, hemoglobin, WBC, white blood cell; ANC, absolute } \\
\text { neutrophil count; AMC, absolute monocyte count; ALC, absolute } \\
\text { lymphocyte count; NLR, neutrophil-lymphocyte ratio; MLR, } \\
\text { monocyte-lymphocyte ratio; PLR, platelet-lymphocyte ratio; SD, } \\
\text { standard deviation }\end{array}$} \\
\hline
\end{tabular}

models suggested that lymphadenectomy could be omitted in patients who were classified as having low risk EC. In contrast, lymphadenectomy was recommended for patients classified as having high risk EC. Li (2019) proposed the model comprising additional biomarker including preoperative serum CA-125 and HE4 to predict lymph node metastasis. They showed that serum CA125 of $27.6 \mathrm{U} / \mathrm{mL}$ or greater, serum HE4 of $132 \mathrm{pmol} / \mathrm{L}$ or greater, and having non-endometrioid histology, myometrial invasion of $50 \%$ or greater, positive peritoneal cytology, and LVSI were independent predictors of PLNM. Stalberg (2017) concluded that non-endometrioid histology, tumor grade 3, and deep myometrial invasion were significantly correlated with PLNM. Kadan (2017) established lower BMI as a significant preoperative risk factor for PLNM in low risk EC patients. Our study demonstrated that myometrial invasion of $50 \%$ or greater and LVSI were independent risk factors for developing PLNM, and EC patients with deep myometrial invasion and LVSI were approximately 9 times and 4 times, respectively more likely to have PLNM. Our study and previous studies (Stalberg et al., 2017; Li et al., 2019) agreed that deep myometrial invasion was a significant co-risk factor for developing PLNM in EC patients. The diagnostic accuracies of magnetic resonance imaging (MRI), ultrasonography, and intraoperative gross examination for assessing the depth of myometrial invasion were $73-83 \%, 68-77 \%$, and $74-87 \%$, respectively (Akbayir et al.,2011; Mavromatis et al., 2012; Christensen et al., 2016; Usta et al., 2017; Jonsdottir et al., 2021). Therefore, we would suggest to utilize both preoperative assessment of myometrial invasion using ultrasonography or MRI, and intraoperative gross myometrial invasion evaluation for selecting patients who would benefit from lymphadenectomy.

Furthermore, blood cell findings including neutrophilia, thrombocytosis and relative lymphopenia have been proposed as noninvasive, inexpensive, and readily accessible tools to predict lymph node
Table 3. Multivariate Analysis of Risk Factors for Pelvic Lymph Node Metastasis

\begin{tabular}{lcc}
\hline Variables & $\begin{array}{c}\text { Odds ratio } \\
(95 \% \text { Confidence interval) }\end{array}$ & P-value \\
\hline $\begin{array}{ccc}\text { Myometrial invasion } \\
<50 \%\end{array}$ & 1 & - \\
$\geq 50 \%$ & $9.31(2.58-33.55)$ & 0.001 \\
LVSI & 1 & - \\
No & $3.73(1.39-10.02)$ & 0.009 \\
Yes &
\end{tabular}

involvement in EC patients (Grivennikov et al., 2010; Suh et al., 2012; McMillan, 2013; Li et al., 2019; Aoyama et al., 2019; Gao and Gao, 2021). Systemic inflammatory response accounts for those changes and represents the development and progression of malignancy (Hanahan and Weinberg, 2011).

Previous studies showed conflicting data regarding NLR and PLR changes in EC patients. Some studies reported that NLR and PLR were higher in lymph nodepositive EC patients as compared with those of lymph node-negative patients (Suh et al., 2012; Gao and Gao, 2021). Kadan (2017) demonstrated that NLR had no significant correlation with nodal metastasis. Univariate analysis of our study did not show the associations of PLNM with ANC, AMC, ALC, NLR, MLR and PLR. However, the pelvic lymph node-positive group had lower $\mathrm{Hb}$ level and higher WBC count than the pelvic lymph node-negative group. Therefore, NLR and PLR might not be a reliable predictor of lymph node metastasis in EC patients.

The strengths of our study are the standard staging surgeries were performed by experienced gynecologic oncologists and the detailed analyses of several clinicopathologic factors that might affect lymph node metastasis were included. However, we acknowledge the limitation of this study which was a single-center retrospective study, potential practice bias could not be excluded.

In conclusion, myometrial invasion of $50 \%$ or greater and LVSI were independent risk factors of PLNM in patients with apparently early-stage EC. Therefore, preoperative assessment of myometrial invasion by using imaging modalities and intraoperative gross myometrial invasion evaluation should be performed to select the EC patients who would benefit from lymphadenectomy.

\section{Author Contribution Statement}

PG, YP and CT designed the research study, acquisition of the data, analysis and interpretation of the data. PG and YP wrote the manuscript. All authors contributed to editorial changes in the manuscript. All authors read and approved the final manuscript.

\section{Acknowledgements}

We would like to thank Tanyawan Chaidarun for 
English language editing.

\section{Funding Statement}

This study was supported by Thammasat University

Research Fund, Contract No. TUFT 38/2564.

\section{Study Approval}

This manuscript is a part of an approved resident thesis by Department of Obstetrics and Gynecology, Faculty of Medicine, Thammasat University Hospital.

\section{Ethical Approval}

The study was approved by the ethical approval from Human Research Ethics Committee of Thammasat University.

\section{Availability of Data}

The datasets used in this study are available from the corresponding author upon reasonable request.

\section{Conflict of Interest}

Authors have no conflict of interest to declare.

\section{References}

Achouri A, Huchon C, Bats AS, et al (2013). Complications of lymphadenectomy for gynecologic cancer. Eur J Surg Oncol, 39, 81-6.

Akbayir O, Corbacioglu A, Numanoglu C, et al (2011). Preoperative assessment of myometrial and cervical invasion in endometrial carcinoma by transvaginal ultrasound. Gynecol Oncol, 122, 600-3.

Aoyama T, Takano M, Miyamoto M, et al (2019). Pretreatment Neutrophil-to-Lymphocyte Ratio Was a Predictor of Lymph node Metastasis in Endometrial Cancer Patients. Oncology, 96, 259-67.

Bendifallah S, Canlorbe G, Raimond E, et al (2014). A clue towards improving the European Society of Medical Oncology risk group classification in apparent early stage endometrial cancer? Impact of lymphovascular space invasion. Br J Cancer, 110, 2640-6.

Benedetti Panici P, Basile S, Maneschi F, et al (2008). Systematic pelvic lymphadenectomy vs. no lymphadenectomy in earlystage endometrial carcinoma: randomized clinical trial. $J$ Natl Cancer Inst, 100, 1707-16.

Christensen JW, Dueholm M, Hansen ES, et al (2016). Assessment of myometrial invasion in endometrial cancer using three-dimensional ultrasound and magnetic resonance imaging. Acta Obstet Gynecol Scand, 95, 55-64.

Concin N, Matias-Guiu X, Vergote I, et al (2021). ESGO/ ESTRO/ESP guidelines for the management of patients with endometrial carcinoma. Int J Gynecol Cancer, 31, 12-39.

Gao M, Gao Y (2021). Value of preoperative neutrophillymphocyte ratio and human epididymis protein 4 in predicting lymph node metastasis in endometrial cancer patients. J Obstet Gynaecol Res, 47, 515-20.

Grivennikov SI, Greten FR, Karin M (2010). Immunity, inflammation, and cancer. Cell, 140, 883-99.

Hanahan D, Weinberg RA (2011). Hallmarks of cancer: the next generation. Cell, 144, 646-74.

Hareyama H, Hada K, Goto K, et al (2015). Prevalence, classification, and risk factors for postoperative lower extremity lymphedema in women with gynecologic malignancies: a retrospective study. Int J Gynecol Cancer, 25, 751-7.
Jemal A, Bray F, Center MM, et al (2011). Global cancer statistics. CA Cancer J Clin, 61, 69-90.

Jonsdottir B, Marcickiewicz J, Borgfeldt C, et al (2021). Preoperative and intraoperative assessment of myometrial invasion in endometrial cancer-A Swedish Gynecologic Cancer Group (SweGCG) Study. Acta Obstet Gynecol Scand, 100, 1526-33.

Kadan Y, Calvino AS, Katz A, et al (2017). Predictors for lymph nodes involvement in low risk endometrial cancer. J Obstet Gynaecol, 37, 514-8.

Karalok A, Turan T, Basaran D, et al (2017). Lymph Node Metastasis in Patients with Endometrioid Endometrial Cancer: Overtreatment Is the Main Issue. Int J Gynecol Cancer, 27, 748-53.

Keys HM, Roberts JA, Brunetto VL, et al (2004). A phase III trial of surgery with or without adjunctive external pelvic radiation therapy in intermediate risk endometrial adenocarcinoma: a Gynecologic Oncology Group Study. Gynecol Oncol, 92, 744-51.

Khuhaprema T, Srivatanakul P, Sriplung H, et al (2007). Corpus Uteri. Cancer in Thailand, 4, 54-5.

Kilgore LC, Partridge EE, Alvarez RD, et al (1995). Adenocarcinoma of the endometrium: survival comparisons of patients with and without pelvic node sampling. Gynecol Oncol, 56, 29-33.

Kitchener H, Swart AM, Qian Q, Amos C, Parmar MK (2009). Efficacy of systematic pelvic lymphadenectomy in endometrial cancer (MRC ASTEC trial): a randomised study. Lancet, 373, 125-36.

Lee J, Kong TW, Paek J, Chang SJ, Ryu HS (2016). Predicting Model of Lymph Node Metastasis Using Preoperative Tumor Grade, Transvaginal Ultrasound, and Serum CA-125 Level in Patients with Endometrial Cancer. Int J Gynecol Cancer, 26, 1630-5.

Li Y, Cong P, Wang P, et al (2019). Risk factors for pelvic lymph node metastasis in endometrial cancer. Arch Gynecol Obstet, 300, 1007-13.

Mavromatis ID, Antonopoulos CN, Matsoukis IL, et al (2012). Validity of intraoperative gross examination of myometrial invasion in patients with endometrial cancer: a metaanalysis. Acta Obstet Gynecol Scand, 91, 779-93.

McMillan DC (2013). The systemic inflammation-based Glasgow Prognostic Score: a decade of experience in patients with cancer. Cancer Treat Rev, 39, 534-40.

National Comprehensive Cancer Network. Uterine Neoplasms (Version 3.2021). Retrieved from http://www.nccn.org/ professionals/physician_gls/pdf/uterine.pdf

Sari ME, Yalcin I, Sahin H, Meydanli MM, Gungor T (2017). Risk factors for paraaortic lymph node metastasis in endometrial cancer. Int J Clin Oncol, 22, 937-44.

Shah PH, Kudrimoti M, Feddock J, Randoll M (2011). Adjuvant treatment for stage IIIc endometrial cancer: options and controversies. Gynecol Oncol, 122, 675-83.

Stalberg K, Kjølhede P, Bjurberg M, et al (2017). Risk factors for lymph node metastases in women with endometrial cancer: A population-based, nation-wide register study-On behalf of the Swedish Gynecological Cancer Group. Int $J$ Cancer, 140, 2693-700.

Suh DH, Kim HS, Chung HH, et al (2012). Pre-operative systemic inflammatory response markers in predicting lymph node metastasis in endometrioid endometrial adenocarcinoma. Eur J Obstet Gynecol Reprod Biol, 162, 206-10.

Usta CS, Usta A, Karacan M, et al (2017). Preoperative MRI versus intraoperative frozen-section in the assessment of myometrial invasion in endometrioid type endometrial cancer. Eur J Gen Med, 14, 9-13. 
Pariyed Gumtorntip et al

Vargas R, Rauh-Hain JA, Clemmer J, et al (2014). Tumor size, depth of invasion, and histologic grade as prognostic factors of lymph node involvement in endometrial cancer: a SEER analysis. Gynecol Oncol, 133, 216-20.

\section{(c) (i) (8)}

This work is licensed under a Creative Commons AttributionNon Commercial 4.0 International License. 